\title{
OPEN Artificial whole genome duplication in paleopolyploid sturgeons yields highest documented chromosome number in vertebrates
}

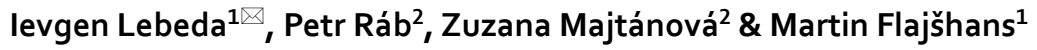

Critically endangered sturgeons, having undergone three whole genome duplication events, represent an exceptional example of ploidy plasticity in vertebrates. Three extant ploidy groups, combined with autopolyploidization, interspecific hybridization and the fertility of hybrids are important issues in sturgeon conservation and aquaculture. Here we demonstrate that the sturgeon genome can undergo numerous alterations of ploidy without severe physiological consequences, producing progeny with a range of ploidy levels and extremely high chromosome numbers. Artificial suppression of the first mitotic division alone, or in combination with suppression of the second meiotic division of functionally tetraploid zygotes ( $4 \mathrm{n}, \mathrm{C}$-value $=4.15$ ) of Siberian sturgeon Acipenser baerii and Russian sturgeon $A$. gueldenstaedtii resulted in progeny of various ploidy levels-diploid/hexaploid $(2 n / 6 n)$ mosaics, hexaploid, octoploid juveniles (8n), and dodecaploid (12n) larvae. Counts between 477 to 520 chromosomes in octoploid juveniles of both sturgeons confirmed the modal chromosome numbers of parental species had been doubled. This exceeds the highest previously documented chromosome count among vertebrates $2 n \sim 446$ in the cyprinid fish Ptychobarbus dipogon.

Polyploidization refers to the multiplication of one or more complete chromosome sets in an organism and represents an important step in evolution and speciation. Polyploidy provides beneficial genetic flexibility and broad adaptive responses, i.e., additional gene copies theoretically allow evolution under reduced selective constraint and the acquisition of novel gene functions that contribute to adaptation ${ }^{1}$. Occurrence of polyploidy in vertebrates is rather sporadic compared to invertebrates and plants, and is mostly restricted to amphibians and ray-finned fishes ${ }^{2,3}$. Ancestral vertebrate genomes likely underwent two rounds (1R and $2 \mathrm{R}$ ) of whole genome duplication $(\mathrm{WGD})^{4-6}$. Teleost fishes then underwent a teleost-specific round of WGD (3R or TSGD) $)^{7,8}$ which is possibly responsible for the great diversity of this group, forming about half of extant vertebrate species ${ }^{9}$. Additional lineage-specific WGD events have occurred independently in several teleostean lineages, e.g., $4 \mathrm{R}$ in Botiidae ${ }^{10}$, Catostomidae $^{11}$, Cyprinidae ${ }^{12,13}$, Callichthyidae ${ }^{14}$ and Salmonidae ${ }^{15}$. These duplication events were associated with increased chromosome numbers from prevailing teleost $2 \mathrm{n}=48-50^{16}$ to roughly (paleo) $4 \mathrm{n}=90-104^{17}$. However, in several lineages of Cyprinidae the already increased $2 \mathrm{n}$ has been raised to around (paleo) $6 \mathrm{n}=150$, i.e., a duplication of a $3 \mathrm{n}$ derivative of the previous (paleo) $4 \mathrm{n} \mathrm{level}{ }^{16}$. The highest chromosome count of any vertebrate to date was documented in Ptychobarbus dipogon, a representative of the schizothoracine cyprinid lineage (Cypriniformes) from the Tibetan Plateau. It possesses 446 chromosomes, representing (paleo)3n derivative of already (paleo) $6 \mathrm{n}^{18}$.

Four basal clades of non-teleostean fishes, i.e., bichirs (Polypteriformes), gars (Lepisosteiformes), bowfin (Amiiformes) and sturgeons and paddlefishes (Acipenseriformes) diverged from the teleosts long before the $\mathrm{TSGD}^{19-22}$. With the exception of Acipenseriformes, none of these ancient lineages underwent further WGD ${ }^{23}$. Of the Acipenseriformes, the Acipenserids (sturgeons) went through up to three rounds of lineage specific WGDs $^{24,25}$, whereas the Polyodontids (paddlefishes) went through only one ${ }^{26}$. The first occurred in the most recent common ancestor of sturgeon and paddlefish with $2 \mathrm{n}=60^{27}$ leading to a $2 \mathrm{n}=\sim 120$ chromosome lineage of 180 (124-225) Ma age ${ }^{28}$. The second lineage specific WGD took place separately in each sturgeon lineage leading

${ }^{1}$ Faculty of Fisheries and Protection of Waters, South Bohemian Research Center of Aquaculture and Biodiversity of Hydrocenoses, Research Institute of Fish Culture and Hydrobiology, University of South Bohemia in České Budějovice, Zátiši 728/II, 38925 Vodňany, Czech Republic. 'Laboratory of Fish Genetics, Institute of Animal Physiology and Genetics, Czech Academy of Sciences, Rumburská 89, 27721 Liběchov, Czech Republic. ${ }^{\square}$ email: ilebeda@frov.jcu.cz 
to two $\sim 240$-chromosome clades ${ }^{25}$ in the Atlantic ( 53 Mya) and Pacific ( $~ 70$ Mya) lineages. The third WGD was unique to the shortnose sturgeon (Acipenser brevirostrum) dated $\sim 35 \mathrm{Mya}^{25}$ and lead to a unique $\sim 360$-chromosome lineage ${ }^{29-31}$. The Polyodontid WGD was very likely of autopolyploid origin, i.e., from within a single species caused by the doubling of homologous genomes, while that of the Acipenserids originated via hybridization events, i.e., allopolyploidy ${ }^{32}$. Despite the fact that each of the ancient non-teleostean groups exhibit very different cytogenomic characteristics ${ }^{23,33}$, the genomes of the Acipenseriformes appear to be the most distinct, with karyotypes composed of macrochromosomes and numerous dot-like microchromosomes of gradually decreasing size ${ }^{34}$.

Nomenclatural problem regarding use of sturgeon polyploidy scale is hotly debated practically in all papers dealing with Acipenseriformes literature and could makes non familiar reader confused. Each metazoan organism that reproduces via fusion of haploid gametes into new diploid organism is biologically diploid, a mechanism associated with evolution of sexual reproduction, irrespective of evolutionary ploidy level of genome. In this sense, biological and evolutionary polyploidy refers to different phenomena and the latter term is meaningful just in phylogenetic context. Recent researchers used, sometime ambiguously, two scales of ploidy level in Acipenseriformes: (i) an evolutionary scale, which assumes (paleo) tetraploid (4n) - (paleo) octoploid (8n) - (paleo) dodecaploid (12n) relationships ${ }^{27}$, and refers to ancient (paleo) ploidy levels; and (ii) a functional scale, which assumes diploid (2n) - tetraploid (4n) - hexaploid (6n) relationships ${ }^{35}$, that originate from significant functional genome re-diploidization during the evolution of sturgeons ${ }^{24,34}$. For clarity, in this study we relate all ploidy levels to the functional scale i.e., normal Siberian and Russian sturgeon are functionally tetraploid, unless other scale specified.

The extraordinary genomic plasticity of sturgeons has been demonstrated through frequent intraspecific hybridization of individuals with different chromosome numbers, resulting in hybrids with intermediate karyotypes ${ }^{36}$. Interestingly, even after hybridization between intermediate hybrids and pure species, the progeny appears fertile to some extent ${ }^{36}$. Moreover, sturgeons are prone to spontaneous polyploidization, with examples found both in nature and aquaculture stocks ${ }^{37-45}$. Through a combination of interspecific hybridization and spontaneous polyploidization, nearly all possible ploidy levels, starting at $\sim 120$ chromosomes and differing in each level by increasing DNA content and a chromosome count of around 30, have been attained in sturgeons ${ }^{22,42,46,47}$. So far, this ploidy chain has reached (paleo) $14 \mathrm{n}$ (corresponding with $7 \mathrm{n}$ in functional ploidy scale) in the progeny of the Siberian sturgeon A. baerii (15.02 \pm 0.04 pg DNA per nucleus and $\sim 437$ chromosomes), and arose through the crossing of a spontaneously paleo-dodecaploid male $(12 \mathrm{n} ; 12.69 \pm 0.43$ pg DNA per nucleus and $\sim 368$ chromosomes) and a paleo-octoploid female (8n; 8.29 \pm 0.05 pg DNA per nucleus and $\sim 245$ chromosomes $)^{48}$, with further suppression of the second polar body extrusion. Also, within the progeny of this cross, a number of individuals with intermediate ploidy levels corresponding to paleo-decaploidy (10n; $8.99 \pm 0.07 \mathrm{pg}$ DNA per nucleus and $\sim 300$ chromosomes; pentaploid $5 \mathrm{n}$ of functional scale) were found ${ }^{42,46,48}$. The fertility of such intermediate and/or odd-number ploidy level individuals spanned from full fertility ${ }^{48}$ to subfertility and even sterility ${ }^{49,50}$. This exceptional natural and induced ploidy plasticity of sturgeon species and/or their hybrids must be considered in aquaculture, since it may represent a much more serious problem for sturgeon farming than currently thought ${ }^{45}$.

The overexploitation of wild populations over the past 150 years has led to the classification of all sturgeon species as critically endangered, and their listing in the Appendices to the Convention on International Trade in Endangered Species of Wild Fauna and Flora (CITES) with 17 of 25 extant species treated as Critically Endangered $^{51}$. The urgent need for conservation action has resulted in the development of sturgeon aquaculture, originally for reintroduction and natural stock reinforcement, but more recently also for commercial purposes (production of meat and caviar) ${ }^{52}$. Since $A$. baerii is the most commonly cultured sturgeon species ${ }^{53,54}$, studies on the high ploidy levels (e.g. ${ }^{42,55}$ ) and their hindering effect on fecundity and physiology contribute to sustainability of sturgeon aquaculture. In this study, we focused on the biological aspects of polyploidization in sturgeons. We developed methods of artificial WGD (AWGD) in functionally tetraploid species of Siberian and Russian sturgeon through suppression of the first mitotic division resulting in viable $8 \mathrm{n}$ juveniles. We determined the karyotypes of these polyploid individuals and detected 477-491 and 483-520 chromosomes in Siberian and Russian sturgeon respectively, confirming that the modal chromosome numbers of the parent species had been doubled. Thus, octoploid Russian and Siberian sturgeon possess the highest chromosome count of any vertebrate documented. Our study expands the general knowledge on polyploidization and documents further enormous ploidy plasticity in sturgeons as compared to other vertebrates.

\section{Results}

Polyploidization. We tested the application of heat shock on fertilized eggs of Siberian and Russian sturgeons to intervene in an extrusion of the second polar body and/or first cleavage division. Treated zygotes showed delayed development (Fig. 1) as well as lower hatching rates (Table 1).

Flow cytometry analysis of relative DNA content showed high variability of the polyploidization treatment efficacy from diploid/hexaploid mosaic to dodecaploid individuals (Table 1, Fig. 2). The AWGD treatment showed increasing efficiency with longer treatment duration in both tested species. Heat shock with a duration of less than $120 \mathrm{~s}$ showed to be insufficient to induce mitotic AWGD. In contrast, treatment with a duration longer than 150 s induced octoploidy in $45 \%$ of the progeny in Russian sturgeon and $38 \%$ of the Siberian sturgeon progeny, but with significantly reduced hatching rates of $15.6 \pm 1.8$ and $15.8 \pm 2.7 \%$, respectively (Table 1 ). Combination of 120 -s-long meiotic shock at $18 \mathrm{~min}$ post-fertilization and $140 \mathrm{~s}$ mitotic shock at 60 min post-fertilization resulted in $66.7 \%$ (6 of 9) dodecaploids in Siberian sturgeon larvae, but these were all malformed and did not survive past yolk sac stage. 

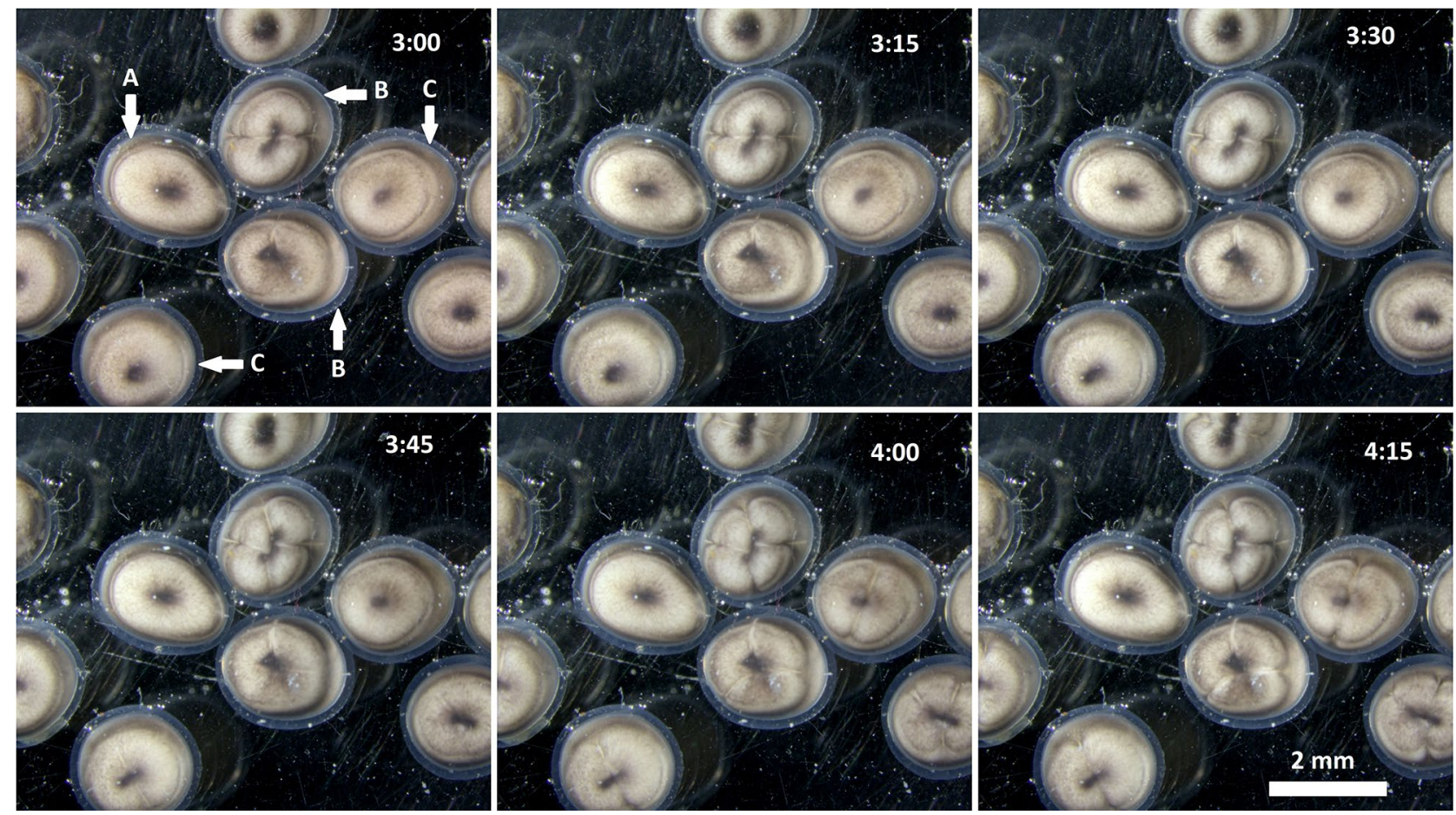

Figure 1. Time-lapse of the first two cleavage divisions of Russian sturgeon zygotes treated with mitotic heat shock showing delayed development of functionally octoploid zygotes. The first photo was taken at the first cleavage division $3 \mathrm{~h}$ after fertilization with subsequent time-lapse capturing in $15 \mathrm{~min}$. Incubation temperature $16{ }^{\circ} \mathrm{C}$. A - unfertilized egg; B - tetraploid zygotes; C - putative octoploid zygotes.

\begin{tabular}{|c|c|c|c|c|c|c|c|c|}
\hline \multirow[b]{2}{*}{ Species } & \multirow{2}{*}{$\begin{array}{l}\text { Meiotic shock, Time } \\
\text { after fertilization (min)/ } \\
\text { Duration (s) }\end{array}$} & \multirow{2}{*}{$\begin{array}{l}\text { Mitotic shock, Time } \\
\text { after fertilization (min)/ } \\
\text { Duration (s) }\end{array}$} & \multirow[b]{2}{*}{ Hatching rate $* \pm \pm$ SD $\%$} & \multirow[b]{2}{*}{$\begin{array}{l}\text { Number of analysed } \\
\text { larvae }\end{array}$} & \multicolumn{4}{|c|}{ Ploidy level } \\
\hline & & & & & $4 n$ & $8 n$ & $12 n$ & $\begin{array}{l}\text { Other (ploidy/ number } \\
\text { of fish) }\end{array}$ \\
\hline \multirow{10}{*}{ Siberian sturgeon } & - & - & $76.6 \pm 0.4, \mathrm{a}$ & 5 & 5 & & & \\
\hline & - & $50 / 110$ & $72.1 \pm 1.3, \mathrm{a}$ & 10 & 10 & & & \\
\hline & - & $50 / 130$ & $21.2 \pm 1.1, \mathrm{~b}$ & 8 & 8 & & & \\
\hline & - & $50 / 150$ & $38.6 \pm 0.3, \mathrm{~b}$ & 10 & 8 & 2 & & \\
\hline & - & $60 / 110$ & $32.4 \pm 2.4, \mathrm{~b}$ & 10 & 10 & & & \\
\hline & - & $60 / 130$ & $36.5 \pm 0.5, \mathrm{~b}$ & 9 & 9 & & & \\
\hline & - & $60 / 150$ & $48.2 \pm 1.5, \mathrm{c}$ & 18 & 11 & 5 & & $2 n+6 n / 2$ \\
\hline & - & $65 / 110$ & $56.7 \pm 2.0, \mathrm{~b}$ & 10 & 10 & & & \\
\hline & - & $65 / 130$ & $24.3 \pm 1.9, \mathrm{c}$ & 10 & 8 & & & $2 n+6 n / 2$ \\
\hline & - & $65 / 150$ & $15.8 \pm 2.7, \mathrm{c}$ & 14 & 3 & 9 & & $2 n+6 n / 2$ \\
\hline \multirow{7}{*}{ Russian sturgeon } & - & - & $94.1 \pm 0.8 \mathrm{a}$ & 5 & 5 & & & \\
\hline & - & $60 / 110$ & $59.6 \pm 1.7, \mathrm{~b}$ & 8 & 8 & & & \\
\hline & - & $60 / 130$ & $21.9 \pm 0.9, \mathrm{c}$ & 9 & 9 & & & \\
\hline & - & $60 / 150$ & $37.3 \pm 0.2, \mathrm{c}$ & 11 & 6 & 4 & & $6 n / 1$ \\
\hline & - & $65 / 110$ & $56.4 \pm 3.2, \mathrm{~b}$ & 10 & 10 & & & \\
\hline & - & $65 / 130$ & $32.2 \pm 2.4, \mathrm{c}$ & 11 & 7 & 4 & & \\
\hline & - & $65 / 150$ & $15.6 \pm 1.8, \mathrm{~d}$ & 29 & 15 & 14 & & \\
\hline \multirow{4}{*}{ Siberian sturgeon } & $18 / 120$ & $60 / 120$ & $16.2 \pm 1.9, \mathrm{~b}$ & 5 & & 1 & & $6 n / 4$ \\
\hline & \begin{tabular}{|l|}
$18 / 120$ \\
\end{tabular} & $60 / 140$ & $3.1 \pm 0.3, \mathrm{c}$ & 9 & 3 & & 6 & \\
\hline & $18 / 120$ & $65 / 120$ & $10.7 \pm 0.8, \mathrm{~b}$ & 2 & 1 & & & $6 n / 1$ \\
\hline & \begin{tabular}{|l|}
$18 / 120$ \\
\end{tabular} & $65 / 140$ & $1.1^{* *}$ & 0 & - & - & - & - \\
\hline
\end{tabular}

Table 1. Hatching rate and flow cytometry analysis results in Siberian and Russian sturgeon progeny subjected to polyploidization treatments. ${ }^{*}$-average hatching rate of three Petri dishes. ${ }^{*}$ - two hatched larvae were found dead. a, b, c, d-significantly different hatching rates in each group, $\mathrm{p}<0.05$, ANOVA, Tukey's test. 

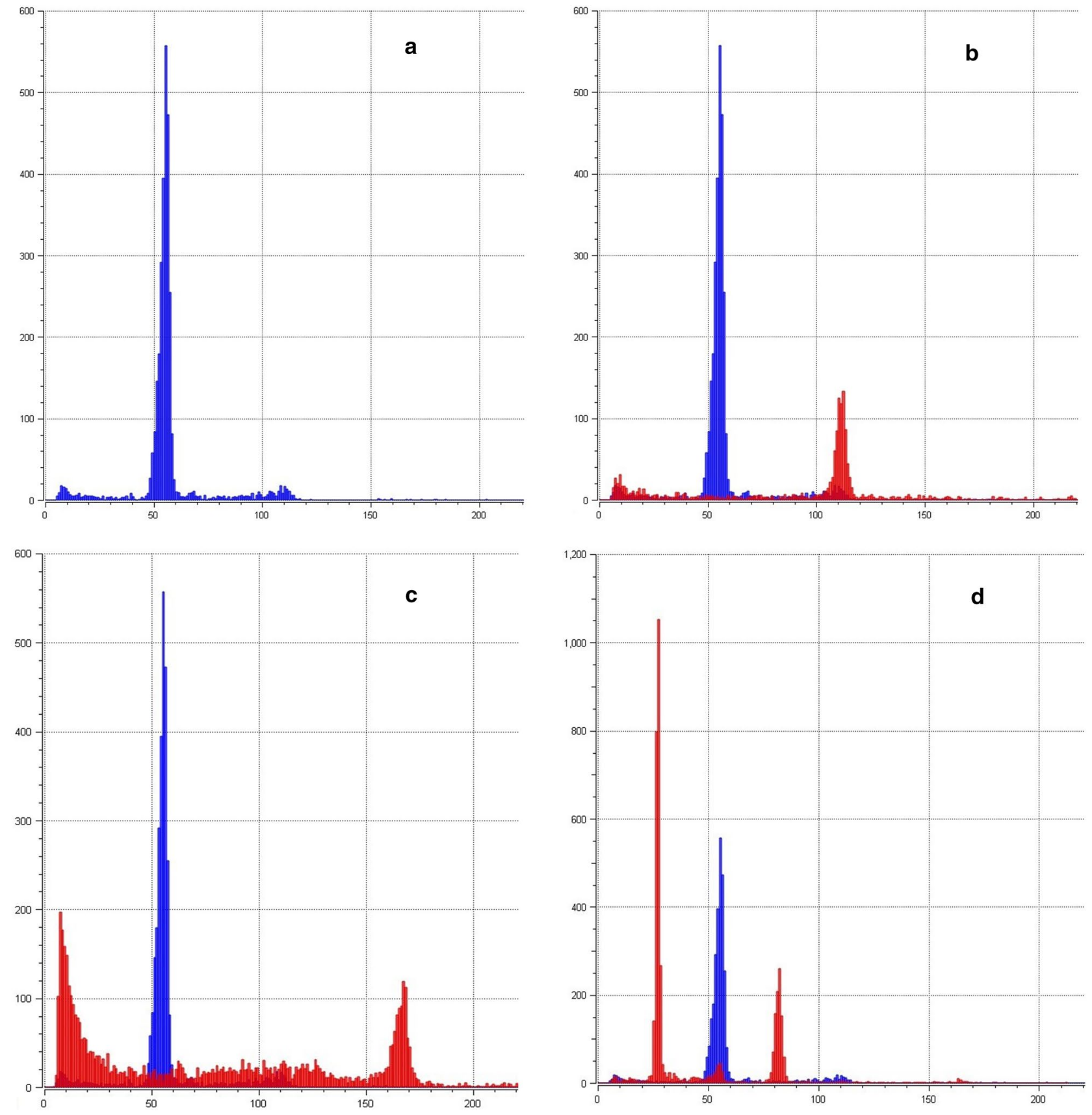

Figure 2. Example of flow cytometry analysis Siberian sturgeon larvae subjected to mitotic and/or meiotic shock and control. (a) Control sample, Siberian sturgeon, functionally tetraploid (4n) is at channel 54.95 (CV 3.19); (b) Functionally octoploid (8n) is at channel 110.96 (CV 2.02) and 4n control; (c) Functionally dodecaploid (12n) is at channel 166.05 (CV 1.93) and 4n control; (d) Diploid/hexaploid mosaic (2n/6n is at channels 26.67 and 81.54 (CV 3.15 and 1.88 respectively) and 4 n control.

Karyotyping. Due to the unique and rare nature of the artificial octoploids and to prevent loss of live individuals, only five individuals of each sturgeon species were used for karyotyping, while metaphase plates from only one Russian and three Siberian sturgeons had enough spreads to permit the identification and counting of the extremely high number of octoploids' chromosomes. Based on the similar DNA content of all individuals, we expect similar chromosome numbers, in agreement with Hardie and Hebert ${ }^{56}$. The karyotype analysis of leucocytes showed the presence of a modal chromosome number of $507.3 \pm 21.1(n=3)$, ranging from 483 to 520 chromosomes per metaphase plate (Fig. 3) in the octoploid Russian sturgeon juvenile, while the number of chromosomes ranged from 477 to 501 with an average $484.3 \pm 11.5(n=6)$ in the three octoploid Siberian sturgeon juveniles (Fig. 4, Table 2).

The observed chromosome numbers correspond to double the chromosomal number of the Russian sturgeon, i.e., $250 \pm 8^{27}$ and Siberian sturgeon, i.e., $245^{42}$, respectively, thus confirming the genome duplication of the 


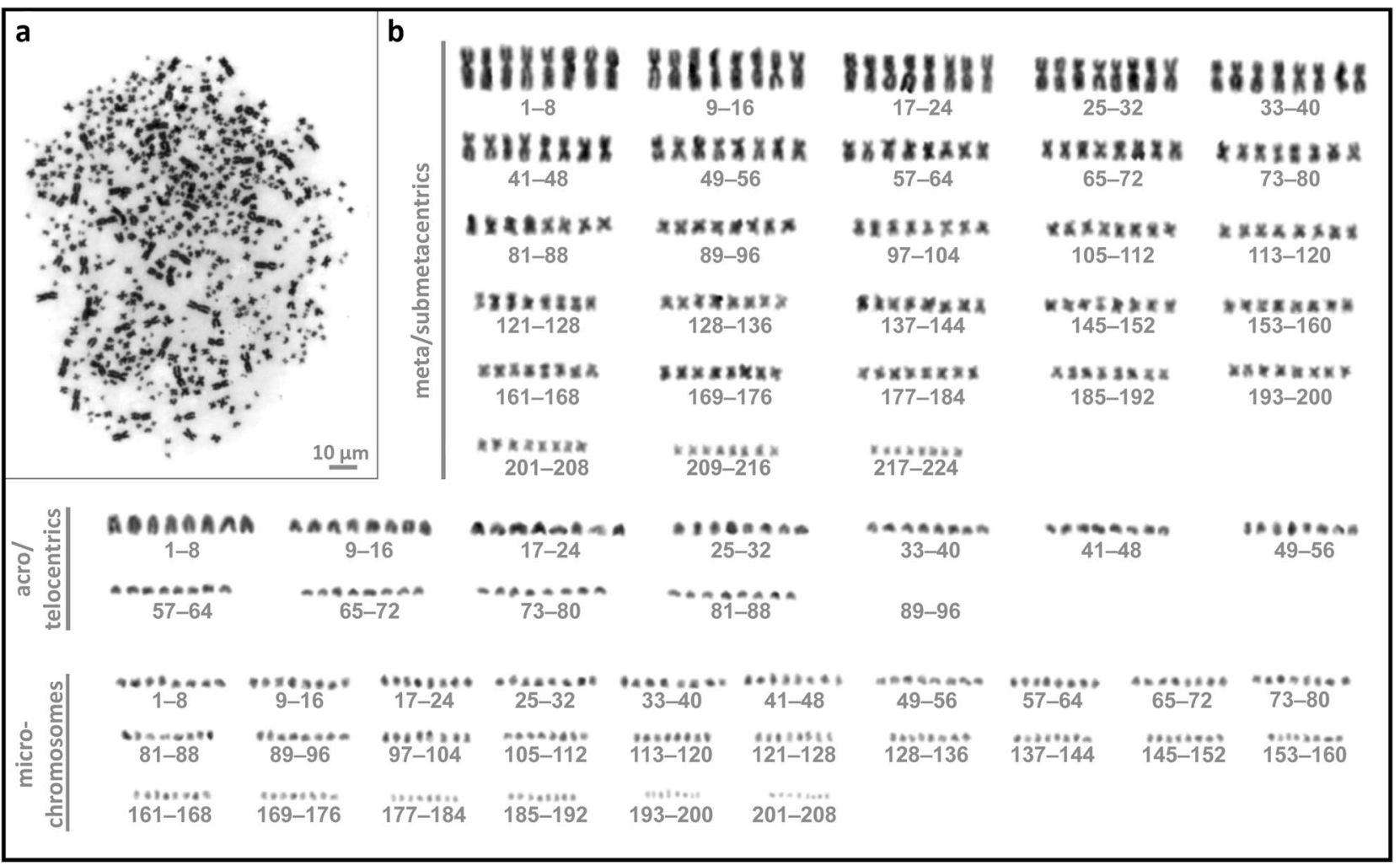

Figure 3. Chromosomes of octoploid Russian sturgeon. (a) Metaphase spread obtained from leucocyte culture of functionally octoploid Siberian sturgeon counting 520 chromosomes; (b) Corresponding karyotype composed of 224 metacentric/submetacentric chromosomes, 88 acrocentric/telocentric chromosomes, and 208 microchromosomes.

parental species. Moreover, the ratios of meta-/acro-/micro-chromosomes were comparable in octoploid and tetraploid individuals, with slight variations in the number attributed to microchromosome counts (Table 2).

\section{Discussion}

Generally, fish with induced WGD through inhibition of the first cell division of the zygote, once the chromosomes have been duplicated shortly after fertilisation, are considered an important source of fertile diploid gametes and as such, they are of great scientific interest ${ }^{57}$. Extremely high embryonic and juvenile mortality rates is the greatest obstacle of such an approach ${ }^{58}$, not only in diploid teleosts but also in sturgeons, as reviewed by Havelka and Arai ${ }^{59}$. Such AWGD organisms may display altered cell architecture and genomic regulatory networks leading to dosage imbalances and abnormal expressions, as concluded by Yin et al. ${ }^{60}$.

In this study, we performed a series of experiments aiming to artificially duplicate ploidy level in Siberian and Russian sturgeons. Using methods of chromosome manipulation, we produced octoploid individuals. The optimum efficiency of AWGD treatment was lower than in our previous study on the Siberian sturgeon and sterlet Acipenser ruthenus, where we observed up to $100 \%$ of octoploid and tetraploid larvae respectively ${ }^{55}$. Additionally, the most efficient duration of AWGD treatment differed from previously reported attempts. Therefore, it could be hypothesized that the efficiency and optimal timing of the AWGD treatment is affected by individual variation based on egg quality and ovulation time, etc. The fact that our method of AWGD treatment was successfully applied to three sturgeon species (namely Russian and Siberian sturgeons and sterlet), suggests this method may also be applicable to other sturgeon species if consideration is given to species specific timing of the first mitotic division.

Based on the results of flow cytometry analysis, we noticed the presence of mosaic individuals containing diploid and hexaploid cells (Fig. 2). The presence of hexaploid individuals in the progeny treated with mitotic heat shock was previously described in a study of AWGD in Siberian sturgeon and sterlet ${ }^{55}$. Such a mosaicism was attributed to arrest in early cell development and was therefore a result of suppression of the second meiotic division instead of the first mitotic division. However, processes responsible for the appearance of mosaic individuals in this study are still not completely understood. Arai and Fujimoto ${ }^{58}$ in their review pointed out the pivotal role of centriole behaviour among cellular mechanisms responsible for induced WGD, when a coexistence of monopolar and bipolar spindles in blastomeres may lead to diploid-tetraploid mosaicism. Analysis of ploidy level in six month old juveniles of Russian and Siberian sturgeon from groups subjected to AWGD showed no mosaicism, or at least no mosaic cells in the fin tissue and blood of studied individuals. This might indicate tissue specificity of diploid cell proliferation, higher mortality of mosaic individuals or the limited proliferation ability of diploid cells in general. 


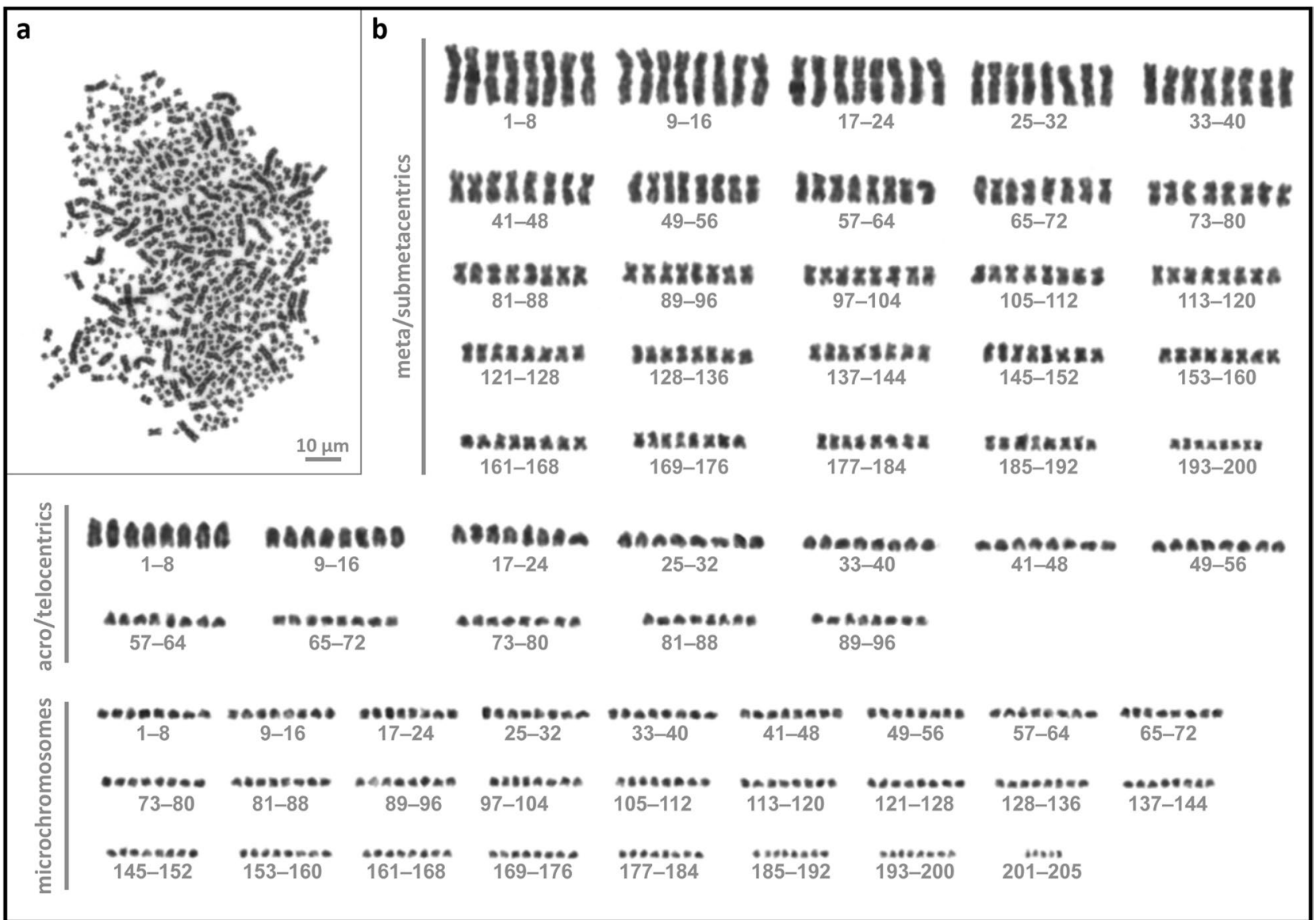

Figure 4. Chromosomes of octoploid Siberian sturgeon. (a) Metaphase spread obtained from leucocyte culture of functionally octoploid Siberian sturgeon counting 501 chromosomes; (b) Corresponding karyotype composed of 200 metacentric/submetacentric chromosomes, 96 acrocentric/telocentric chromosomes, and 205 microchromosomes.

\begin{tabular}{|c|c|c|c|c|c|c|}
\hline & \multirow{2}{*}{\begin{tabular}{|l} 
Individual fish \# \\
1
\end{tabular}} & \multicolumn{2}{|c|}{$\begin{array}{l}\text { Chromosome numbers/ } \\
\text { metaphase plate }\end{array}$} & \multirow{2}{*}{\begin{tabular}{|l|}
$\begin{array}{l}\text { Metacentric } \\
\text { chromosomes }\end{array}$ \\
224 \\
\end{tabular}} & \multirow{2}{*}{\begin{tabular}{|l|}
$\begin{array}{l}\text { Acrocentric } \\
\text { chromosomes }\end{array}$ \\
88 \\
\end{tabular}} & \multirow{2}{*}{\begin{tabular}{|l|}
$\begin{array}{l}\text { Micro } \\
\text { chromosomes }\end{array}$ \\
208 \\
\end{tabular}} \\
\hline & & 520 & & & & \\
\hline \multirow{3}{*}{ Russian sturgeon } & 1 & 483 & & 176 & 108 & 199 \\
\hline & 1 & 519 & & 210 & 120 & 189 \\
\hline & Mean \pm SD & \multicolumn{2}{|c|}{$507.3 \pm 21.1$} & $203.3 \pm 24.7$ & $105.3 \pm 16.2$ & $198.7 \pm 9.5$ \\
\hline \multirow{7}{*}{ Siberian sturgeon } & 2 & 491 & \multirow{2}{*}{$\begin{array}{l}\text { Mean } \pm \text { SD } \\
496 \pm 7.1\end{array}$} & 200 & 144 & 147 \\
\hline & 2 & 501 & & 200 & 96 & 205 \\
\hline & 3 & 469 & & 172 & 84 & 213 \\
\hline & 4 & 489 & \multirow{3}{*}{$\begin{array}{l}\text { Mean } \pm \text { SD } \\
481.7 \pm 6.4\end{array}$} & 192 & 96 & 201 \\
\hline & 4 & 479 & & 172 & 96 & 211 \\
\hline & 4 & 477 & & 166 & 84 & 227 \\
\hline & Mean \pm SD & \multicolumn{2}{|c|}{$482.2 \pm 13.5$} & $176.7 \pm 15.4$ & $92 \pm 22.3$ & $213 \pm 27.8$ \\
\hline
\end{tabular}

Table 2. Karyotyping of Russian and Siberian sturgeon juveniles subjected to artificial whole genome duplication treatment.

Octoploid embryos were identified based on the delayed first and second cleavage division (Fig. 1) with the assumption that the majority of octoploid eggs would have stunted development due to the effects of delaying the first mitotic division. A similar technique was used in ploidy manipulations of zebrafish ${ }^{61,62}$. However, such delayed development could be the result of parthenogenetic activation of eggs ${ }^{63}$ and as a result unfertilized parthenogenetically activated eggs can be misidentified as octoploid.

It is known that throughout their evolutionary history sturgeons have undergone three events of whole genome duplication which gave rise to diploid and tetraploid groups, and hexaploid group ${ }^{34}$. Interestingly, while 
this study demonstrates that further genome duplication is possible, there is no evidence of the appearance of functionally octoploid (8n) sturgeons in the wild, although, the appearance of hexaploid individuals in otherwise functionally tetraploid sturgeon species has been reported ${ }^{64}$. This might be explained as triploidization by meiotic shock (hexaploidization in the case of functionally tetraploid species) could be induced by lower temperatures than tetraploidization by mitotic shock, thus we could expect that likelihood of spontaneous triploidization in nature might be higher. Taking into account that recent decreases in population size would allow for genetic drift to maintain ploidy shifts at a greater rate, we might expect the appearance of octoploid lineages. The absence of octoploid (8n) sturgeons in nature could potentially be caused by negative effects of large genomes on fitness. However, the design of our study was not focused on comparing the fitness of octoploid and tetraploid individuals, thus we cannot confirm any effects of octoploidy on fitness, other than a high level of malformed larvae that were unable to start feeding and died after the disappearance of their yolk sac.

Recent vertebrates display a wide variability in chromosome numbers. In mammals, the chromosome number ranges from $2 \mathrm{n}=6$ to 8 in the female Muntiacus muntjak ${ }^{65,66}$ to $2 \mathrm{n}=102$ in Tympanoctomys barrerae ${ }^{67}$, but most mammals have chromosome numbers within the range of $2 n=36$ to $60^{68}$. Bird karyotypes vary between $2 n=40$ chromosomes in Falco columbarius ${ }^{69}$ to $2 \mathrm{n}=138$ in Alcedo atthis ${ }^{70}$ and peak among $2 \mathrm{n}=80$ chromosomes $^{71}$. In reptiles including crocodiles, turtles, tuataras and squamate reptiles, chromosome number ranges between 24-70 chromosomes $^{72}$. Finally, the highest numbers of chromosomes with the highest variability were described in the more basal groups of vertebrates i.e., fish and amphibians (reviewed by ${ }^{2,17}$ ) in which the highest chromosome number observed was in the cyprinid species Ptychobarbus dipogon $2 \mathrm{n} \sim 446^{18}$. From an evolutionary point of view, it is remarkable then, that our experiments with ploidy manipulation yielded individuals with the highest chromosome count known among vertebrates.

\section{Methods}

Ethics declaration. The fish used in this experiment originated from the Genetic Fisheries Centre, Faculty of Fisheries and Protection of Waters in Vodňany, Czech Republic. The experimental protocol of the study went through an ethical review process and was approved by the expert committee of the Institutional Animal Care and Use Committee in the University of South Bohemia, according to the law on the protection of animals against cruelty (Act no. 246/1992 Coll., ref. number 16OZ15759/2013-17214). To decrease fish suffering during handling, the fish were anaesthetized using $0.07 \mathrm{ml} \mathrm{l}^{-1}$ of clove oil.

Fish and gamete treatment. All broodstock used in this study was subjected to flow cytometry analysis of ploidy level similar as was described for larvae. The gametes were obtained from two Siberian sturgeon females, one Russian sturgeon female, and three males of each species according to previously published methods ${ }^{73,74}$. A normal $(4 \mathrm{n})$ ploidy level was confirmed in all broodstock used in this study, using flow cytometry method described below. The eggs from the two Siberian sturgeon females were pooled, as was the sperm from the three males (separately for each species), prior to fertilization. For fertilization of each experimental group, $10 \mathrm{~g}$ of eggs were mixed with $25 \mathrm{ml}$ of water and $200 \mu \mathrm{l}$ of sperm of the same species. The eggs were fertilized for $2 \mathrm{~min}$ with gentle stirring at $50 \mathrm{rpm}$, and then were distributed into three Petri dishes. Less than one hour elapsed between the first and the last fertilization. After fertilization, Petri dishes with eggs were immersed into incubators at $16^{\circ} \mathrm{C}$ until heat shock. The heat shock was induced by transferring Petri dishes to preheated $37^{\circ} \mathrm{C}$ incubation water for 1.5-2.5 min, according to previously a published protocol of tetraploidization in sterlet and Siberian sturgeon (Table 1$)^{55}$. After heat shock, Petri dishes with eggs were incubated at $16^{\circ} \mathrm{C}$. Fertilization rate was assessed by observation of the first cleavage division under a binocular microscope at $3-4 \mathrm{~h}$ after fertilization. The dead eggs were removed based on absence of neurulation at the third day after fertilisation. Hatching rate data were analysed by one-way ANOVA followed by a Tukey's post-hoc test for comparisons of mean $(n=3$ Petri dishes per treatment), using Statistica 9 software. The level of significance was set at 0.05 .

Ploidy level measurement. In order to determine the success of the AWGD treatment, we analysed the relative DNA content of hatched larvae (equal numbers from each triplicate Petri dish) until at least 15 larvae were selected from experimental group, or until all hatched larvae were analysed. The analysis was performed using minced tissue from part of the caudal fin. Minced tissue was lysed with Nuclei Extraction Buffer (CyStain DNA 2step, Partec GmbH, Germany), and stained with fluorescent DNA dye, the 4', 6-diamidino-2-phenylindol (DAPI). We used a Partec Cell Counter Analyser (Partec GmbH, Germany) to estimate the relative DNA content per cell. The untreated larvae of diploid A. ruthenus were used as a reference sample. At least 2000 nuclei from each sample were analysed with the flow-through rate $0.5-1.0 \mu \mathrm{l} \mathrm{s}^{-1}$. Combined histograms were produced by overlaying raw data in ${ }^{\star}$.fcs format using CYTO-SW 0.3 software (Wolf \& Danniel s.r.o., Czech Republic).

Chromosome preparations from juveniles. We followed the protocol by Völker and Ráb ${ }^{75}$ with significant modifications for the preparation of sturgeon chromosomes. Venous blood $(0.5 \mathrm{ml})$ was collected from an anesthetized fish using a heparinized sterile syringe. The leucocyte-rich plasma was used to set up primary cultures in $5 \mathrm{ml}$ of the Medium 199 (Sigma, St. Louis, Mo., USA) supplemented with 10\% fetal calf serum (FBS Superior, Biochrom, Berlin, Germany), 1\% Antibiotic Antimycotic Solution (Sigma), LPS from E. coli $(0.1 \mathrm{mg} / \mathrm{ml}$ of medium), PHA-P (18 $\mu \mathrm{g} / \mathrm{ml}$ of medium; Remel, Lenexa, Kans., USA), Kanamycin $(0.06 \mathrm{mg} / \mathrm{ml}$ of medium; Sigma) and $0.175 \mu \mathrm{l} 10 \%$ mercaptoethanol (Sigma). After $120 \mathrm{~h}$ of incubation at $20^{\circ} \mathrm{C}, 5 \mathrm{ml}$ of each culture was harvested using standard colchicine ( 2 drops of $0.1 \%$ colchicine per $5 \mathrm{ml}$ of medium) and hypotonic $(8 \mathrm{~min})$ treatments followed by 3 rounds of fixation in freshly prepared fixative (methanol: acetic acid $3: 1$, v/v) and finally dropped on cleaned microscope slides. Chromosomal preparations were stained with Giemsa solution $(5 \%, 10 \mathrm{~min})$ to visualize the chromosomes. 
Karyotyping and image processing. Chromosomal preparations were examined using an Olympus Provis AX 70 epifluorescence microscope and images of metaphase chromosomes were recorded with a cooled Olympus DP30BW CDD camera. Well-spread metaphase chromosomes were arranged in karyotypes using Ikaros MetaSystem (Metasystems, Altlussheim, Germany) and superimposed using Adobe Photoshop software, version CS5.

Received: 7 July 2020; Accepted: 28 October 2020

Published online: 12 November 2020

\section{References}

1. Panchy, N., Lehti-Shiu, M. \& Shiu, S. H. Evolution of gene duplication in plants. Plant. Physiol. 171, 2294-2316 (2016).

2. Mable, B. K., Alexandrou, M. A. \& Taylor, M. I. Genome duplication in amphibians and fish: an extended synthesis. J. Zool. 284, 151-182 (2011).

3. Comai, L. The advantages and disadvantages of being polyploid. Nat. Rev. Genet. 6, 836-846 (2005).

4. Ohno, S. Evolution by gene duplication. (Springer, New York, 1970).

5. Lynch, M. Genomics. Gene Duplication and Evolution. Science (New York, N.Y.) vol. 297 https://pubmed.ncbi.nlm.nih.gov/12169 $715 /(2002)$.

6. McLysaght, A., Hokamp, K. \& Wolfe, K. H. Extensive genomic duplication during early chordate evolution. Nat. Genet. 31, 200-204 (2002).

7. Venkatesh, B. Evolution and diversity of fish genomes. Curr. Opin. Genet. Dev. 13, 588-592 (2003).

8. Hoegg, S., Brinkmann, H., Taylor, J. S. \& Meyer, A. Phylogenetic timing of the fish-specific genome duplication correlates with the diversification of teleost fish. J. Mol. Evol. 59, 190-203 (2004).

9. Nelson, J. S., Grande, T. C. \& Wilson, M. V. H. Fishes of the World. (Wiley, Hoboken, 2016).

10. Šlechtová, V., Bohlen, J., Freyhof, J. \& Ráb, P. Molecular phylogeny of the Southeast Asian freshwater fish family Botiidae (Teleostei: Cobitoidea) and the origin of polyploidy in their evolution. Mol. Phylogenet. Evol. 39, 529-541 (2006).

11. Uyeno, T. \& Smith, G. Tetraploid origin of karyotype of Catostomid fishes. Science 175, 644- (1972).

12. David, L., Blum, S., Feldman, M. W., Lavi, U. \& Hillel, J. Recent duplication of the common carp (Cyprinus carpio L.) genome as revealed by analyses of microsatellite loci. Mol. Biol. Evol. 20, 1425-1434 (2003).

13. Yang, L. et al. Phylogeny and polyploidy: resolving the classification of cyprinine fishes (Teleostei: Cypriniformes). Mol. Phylogenet. Evol. 85, 97-116 (2015).

14. Alexandrou, M. A. et al. Competition and phylogeny determine community structure in Müllerian co-mimics. Nature 469, $84-88$ (2011).

15. Macqueen, D. J. \& Johnston, I. A. A well-constrained estimate for the timing of the salmonid whole genome duplication reveals major decoupling from species diversification. Proc. R. Soc. B. 281, 20132881 (2014).

16. Mank, J. E. \& Avise, J. C. Phylogenetic conservation of chromosome numbers in Actinopterygiian fishes. Genetica 127, 321-327 (2006).

17. Arai, R. Fish karyotypes: a check list. (Springer, New York, 2011).

18. Yu, X. \& Yu, X. A schizothoracine fish species diptychus dipogon with a very high number of chromosomes. Chromosome Inf. Service 48, 17-18 (1990).

19. Froschauer, A., Braasch, I. \& Volff, J. N. Fish genomes, comparative genomics and vertebrate evolution. Curr. Genomics 7, 43-57 (2006).

20. Amores, A., Catchen, J., Ferrara, A., Fontenot, Q. \& Postlethwait, J. H. Genome evolution and meiotic maps by massively parallel DNA sequencing: spotted gar, an outgroup for the teleost genome duplication. Genetics 188, 799-808 (2011).

21. Sallan, L. C. Major issues in the origins of ray-finned fish (Actinopterygii) biodiversity. Biol. Rev. 89, 950-971 (2014).

22. Havelka, M., Kašpar, V., Hulák, M. \& Flajšhans, M. Sturgeon genetics and cytogenetics: a review related to ploidy levels and interspecific hybridization. Folia Zool. https://doi.org/10.25225/fozo.v60.i2.a3.2011 (2011).

23. Symonová, R. et al. Genome compositional organization in gars shows more similarities to mammals than to other ray-finned fish. J. Exp. Zool. B Mol. Dev. Evol. 328, 607-619 (2017).

24. Ludwig, A., Belfiore, N. M., Pitra, C., Svirsky, V. \& Jenneckens, I. Genome duplication events and functional reduction of ploidy levels in sturgeon (Acipenser, Huso and Scaphirhynchus). Genetics 158, 1203-1215 (2001).

25. Peng, Z. et al. Age and biogeography of major clades in sturgeons and paddlefishes (Pisces : Acipenseriformes). Mol. Phylogenet. Evol. 42, 854-862 (2007).

26. Dingerkus, G. \& Howell, W. M. Karyotypic analysis and evidence of tetraploidy in the North American paddlefish, Polyodon spathula. Science 194, 842-844 (1976).

27. Birstein, V. J. \& Vasiliev, V. P. Tetraploid-octoploid relationships and karyological evolution in the order Acipenseriformes (Pisces) karyotypes, nucleoli, and nucleolus-organizer regions in four acipenserid species. Genetica 72, 3-12 (1987).

28. Du, K. et al. The sterlet sturgeon genome sequence and the mechanisms of segmental rediploidization. Nat. Ecol. Evol. 4, 841-852 (2020).

29. Kim, D. S., Nam, Y. K., Noh, J. K., Park, C. H. \& Chapman, F. A. Karyotype of North American shortnose sturgeon Acipenser brevirostrum with the highest chromosome number in the Acipenseriformes. Icht. Res. https://doi.org/10.1007/s10228-004-0257-Z (2004).

30. Fontana, F. et al. Evidence of hexaploid karyotype in shortnose sturgeon. Genome 51, 113-119 (2008).

31. Birstein, V. J., Hanner, R. \& DeSalle, R. Phylogeny of the Acipenseriformes: cytogenetic and molecular approaches. Environ. Biol. Fishes 48, 127-155 (1997).

32. Vasil'ev, V. P. Mechanisms of polyploid evolution in fish: polyploidy in sturgeons. in Biology, Conservation and Sustainable Development of Sturgeons (eds. Carmona, R. et al.) 97-117 (Springer Netherlands, 2009). doi:https://doi.org/10.1007/978-1-4020-8437-9_6.

33. Majtánová, Z., Symonová, R., Arias-Rodriguez, L., Sallan, L. \& Ráb, P. 'Holostei versus Halecostomi' problem: Insight from cytogenetics of ancient nonteleost actinopterygian fish, bowfin Amia calva. J. Exp. Zool. B Mol. Dev. Evol. 328, 620-628 (2017).

34. Fontana, F., Zane, L., Pepe, A. \& Congiu, L. Polyploidy in Acipenseriformes: cytogenetic and molecular approaches. in Fish Cytogen. (eds. Pisano, E., Ozouf-Costaz, C., Foresti, F. \& Kapoor, B. G.) 385-403 (Science Publisher, 2007).

35. Vasil'eva, E. D., Vasil'ev, V. P., Ponomareva, E. N. \& Lapukhin, Yu. A. Triple hybrids obtained by artificial hybridization of the Russian sturgeon Acipenser gueldenstaedtii with the hybrid of the starred sturgeon A stellatus and the great sturgeon A. huso (Acipenseridae): The kind of inheritance of some morphological characters and fertility of the parental hybrid form. J. Ichthyol. 50, 605-617 (2010).

36. Omoto, N., Maebayashi, M., Adachi, S., Arai, K. \& Yamauchi, K. The influence of oocyte maturational stage on hatching and triploidy rates in hybrid (bester) sturgeon, Huso huso $\times$ Acipneser ruthenus. Aquaculture 245, 287-294 (2005).

37. Schreier, A. D., Gille, D., Mahardja, B. \& May, B. Neutral markers confirm the octoploid origin and reveal spontaneous autopolyploidy in white sturgeon, Acipenser transmontanus. J. Appl. Ichthyol. 27, 24-33 (2011). 
38. Zhou, H., Fujimoto, T., Adachi, S., Yamaha, E. \& Arai, K. Genome size variation estimated by flow cytometry in Acipenser mikadoi, Huso dauricus in relation to other species of Acipenseriformes. J. Appl. Ichthyol. 27, 484-491 (2011).

39. Zhou, H. et al. Molecular cytogenetic study on the ploidy status in Acipenser mikadoi. J. Appl. Ichthyol. 29, 51-55 (2013).

40. Schreier, A. D., Mahardja, B. \& May, B. Patterns of population structure vary across the range of the white sturgeon. Trans. Am. Fish. Soc. 142, 1273-1286 (2013).

41. Havelka, M. et al. Fertility of a spontaneous hexaploid male Siberian sturgeon, Acipenser baerii. BMC Genet. 15, 5 (2014).

42. Gille, D. A., Famula, T. R., May, B. P. \& Schreier, A. Evidence for a maternal origin of spontaneous autopolyploidy in cultured white sturgeon (Acipenser transmontanus). https://doi.org/10.1016/j.aquaculture.2014.10.002 (2015).

43. Havelka, M., Hulák, M., Rodina, M. \& Flajšhans, M. First evidence of autotriploidization in sterlet (Acipenser ruthenus). J. Appl. Genetics. 54, 201-207 (2013).

44. Van Eenennaam, J. P. et al. Mechanical shock during egg de-adhesion and post-ovulatory ageing contribute to spontaneous autopolyploidy in white sturgeon culture (Acipensertransmontanus). Aquaculture 515, 734530 (2020).

45. Bytyutskyy, D., Srp, J. \& Flajšhans, M. Use of Feulgen image analysis densitometry to study the effect of genome size on nuclear size in polyploid sturgeons. J. Appl. Ichthyol. 28, 704-708 (2012).

46. Symonová, R. et al. Sturgeons are pretty polyploid: hybrid and ploidy diversity in sturgeons. in Book of Abstracts KN1 pp 13 (2010).

47. Havelka, M., Bytyutskyy, D., Symonová, R., Ráb, P. \& Flajšhans, M. The second highest chromosome count among vertebrates is observed in cultured sturgeon and is associated with genome plasticity. Genet. Select. Evol. 48, 12 (2016).

48. Linhartová, Z., Havelka, M., Pšenička, M. \& Flajšhans, M. Interspecific hybridization of sturgeon species affects differently their gonadal development. Czech J. Anim. Sci. 63(2018), 1-10 (2017).

49. Shivaramu, S. et al. Influence of interspecific hybridization on fitness-related traits in Siberian sturgeon and Russian sturgeon. Czech J. Anim. Sci. 64(2019), 78-88 (2019).

50. IUCN. The IUCN Red List of Threatened Species. (2020).

51. Pikitch, E. K., Doukakis, P., Lauck, L., Chakrabarty, P. \& Erickson, D. L. Status, trends and management of sturgeon and paddlefish fisheries. Fish Fish. 6, 233-265 (2005).

52. Bronzi, P. \& Rosenthal, H. Present and future sturgeon and caviar production and marketing: a global market overview. J. Appl. Ichthyol. 30, 1536-1546 (2014).

53. Bronzi, P., Rosenthal, H. \& Gessner, J. Global sturgeon aquaculture production: an overview. J. Appl. Ichthyol. 27, 169-175 (2011).

54. Lebeda, I. \& Flajshans, M. Technical note: production of tetraploid sturgeons. J. Anim. Sci. 93, 3759-3764 (2015).

55. Fontana, F. Chromosomal nucleolar organizer regions in four sturgeon species as markers of karyotype evolution in Acipenseriformes (Pisces). Genome 37, 888-892 (1994).

56. Hardie, D. C. \& Hebert, P. D. N. The nucleotypic effects of cellular DNA content in cartilaginous and ray-finned fishes. Genome 46, 683-706 (2003).

57. Piferrer, F. et al. Polyploid fish and shellfish: production, biology and applications to aquaculture for performance improvement and genetic containment. Aquaculture 293, 125-156 (2009).

58. Arai, K. \& Fujimoto, T. Chromosome manipulation techniques and applications to aquaculture. in Sex Control in Aquaculture 137-162 (Wiley, Hoboken, 2018). doi:https://doi.org/10.1002/9781119127291.ch6.

59. Havelka, M. \& Arai, K. Hybridization and polyploidization in sturgeon. in Sex Control in Aquaculture 669-687 (Wiley, Hoboken, 2018). doi:https://doi.org/10.1002/9781119127291.ch34.

60. Yin, F. et al. CRISPR/Cas9 Application for gene copy fate survey of polyploid vertebrates. Front. Genet. 9, (2018).

61. Heier, J., Takle, K. A., Hasley, A. O. \& Pelegri, F. Ploidy manipulation and induction of alternate cleavage patterns through inhibition of centrosome duplication in the early zebrafish embryo. Develop. Dynam. 244, 1300-1312 (2015).

62. Yabe, T., Ge, X. \& Pelegri, F. The zebrafish maternal-effect gene cellular atoll encodes the centriolar component sas- 6 and defects in its paternal function promote whole genome duplication. Develop. Biol. 312, 44-60 (2007).

63. Dettlaff, T. A., Ginsburg, A. S. \& Schmalhausen, O. I. Embryonic development. in Sturgeon Fishes: Developmental Biology and Aquaculture (eds. Dettlaff, T. A., Ginsburg, A. S. \& Schmalhausen, O. I.) 49-154 (Springer, New York, 1993). doi:https://doi. org/10.1007/978-3-642-77057-9_3.

64. Blacklidge, K. H. \& Bidwell, C. A. Three ploidy levels indicated by genome quantification in Acipenseriformes of North America. J. Hered. 84, 427-430 (1993).

65. Wurster, D. H. \& Atkin, N. B. Muntjac chromosomes: a new karyotype for Muntiacus muntjak. Experientia 28, 972-973 (1972).

66. Wurster, D. H. \& Benirschke, K. Indian momtjac, Muntiacus muntiak: A deer with a low diploid chromosome number. Science 168, 1364-1366 (1970).

67. Gallardo, M. H., González, C. A. \& Cebrián, I. Molecular cytogenetics and allotetraploidy in the red vizcacha rat, Tympanoctomys barrerae (Rodentia, Octodontidae). Genomics 88, 214-221 (2006).

68. Schmid, M., Fernández-Badillo, A., Feichtinger, W., Steinlein, C. \& Roman, J. I. On the highest chromosome number in mammals. Cytogenet. Cell Genet. 49, 305-308 (1988).

69. Nishida, C. et al. Characterization of chromosome structures of Falconinae (Falconidae, Falconiformes, Aves) by chromosome painting and delineation of chromosome rearrangements during their differentiation. Chromosome Res. 16, 171-181 (2008).

70. Bian, X. \& Li, Q. Studies on The karyotypes of birds V. The 20 species of Climber birds.(Aves). zr 10, 309-317 (1989).

71. Masabanda, J. S. et al. Molecular cytogenetic definition of the chicken genome: the first complete avian karyotype. Genetics 166, 1367-1373 (2004).

72. Olmo, E. Rate of chromosome changes and spe ciation in reptiles. Genetica 125, 185-203 (2005).

73. Gela, D., Rodina, M. \& Linhart, O. Artificial reproduction of sturgeon (Acipenseridae). in Edice Metodik pp 24 (2008).

74. Lebeda, I., Dzyuba, B., Rodina, M. \& Flajshans, M. Optimization of sperm irradiation protocol for induced gynogenesis in Siberian sturgeon, Acipenser baerii. Aquacult. Int. 22, 485-495 (2014).

75. Völker, M. \& Ráb, P. Direct chromosome preparation from regenerating fin tissue. in Fish Cytogenetic Techniques (eds. OzoufCostaz, C., Pisano, E., Foresti, F. \& Foresti de Almeida-Toledo, L.) 37-41 (CRC Press, Boca Raton, 2015).

\section{Acknowledgements}

The study was financially supported by the Czech Science Foundation project No. 18-09323S, by the Ministry of Education, Youth and Sports of the Czech Republic project Biodiversity (CZ.02.1.01/0.0/0.0/16_025/0007370), and Project EXCELLENCE CZ.02.1.01/0.0/0.0/15_003/0000460 OP RDE, RVO: 67985904. Grant agencies had no participation in the design of the study or interpretation of the results.

\section{Author contributions}

M.F. and I.L. conceptualized and designed the study. I.L. and M.F. performed the experiments, flow cytometric analyses and analysed the data. P.R., Z.M. and I.L. performed cytogenetic analyses and co-draft the manuscript together with M.F. All co-authors revised the text and agreed to the final version. The authors declare no competing interests. 


\section{Competing interests}

The authors declare no competing interests.

\section{Additional information}

Correspondence and requests for materials should be addressed to I.L.

Reprints and permissions information is available at www.nature.com/reprints.

Publisher's note Springer Nature remains neutral with regard to jurisdictional claims in published maps and institutional affiliations.

(c) (1) Open Access This article is licensed under a Creative Commons Attribution 4.0 International License, which permits use, sharing, adaptation, distribution and reproduction in any medium or format, as long as you give appropriate credit to the original author(s) and the source, provide a link to the Creative Commons licence, and indicate if changes were made. The images or other third party material in this article are included in the article's Creative Commons licence, unless indicated otherwise in a credit line to the material. If material is not included in the article's Creative Commons licence and your intended use is not permitted by statutory regulation or exceeds the permitted use, you will need to obtain permission directly from the copyright holder. To view a copy of this licence, visit http://creativecommons.org/licenses/by/4.0/.

(c) The Author(s) 2020 